\title{
Use of patient-reported outcome measures (PROMs) by orthopedic surgeons in Saudi Arabia
}

\author{
Fayez Alshehri ${ }^{1 *}$ D, Abdulaziz Alarabi ${ }^{1}$, Mohammed Alharthi', Thamer Alanazi ${ }^{1}$, Ahmed Alohali ${ }^{1}$ and \\ Mohammad Alsaleem²
}

\begin{abstract}
Background: There is increasing literature on the usefulness of patient-reported outcome measures (PROMs), but far fewer studies to determine their use by orthopedic surgeons and the barriers they face in applying PROMs in their daily clinical activity.

Methods: Cross-sectional study using a questionnaire that was distributed in both soft and hard copy formats to a sample of 262 orthopedic surgeons. Participants included orthopedic surgeons who are employed by the Ministry of Health $(\mathrm{MOH})$ in Riyadh and the Eastern Province, Saudi Arabia. The questionnaire was distributed through onsite visitations to orthopedic departments in $\mathrm{MOH}$ hospitals as well as through online correspondence by email, WhatsApp, and social media.

Results: The study sample included 262 orthopedic surgeons (13.7\% females and $86.3 \%$ males). Surgeons aged $<34,35-44$, and $45-54$ years old represented $28.66 \%, 38.9 \%$, and $20.2 \%$ of the study sample, respectively. The majority of the included surgeons did not use PROMs (69.1\%), and some (17.2\%) used it for research purposes. Only 5\% used it regularly in daily clinical work.

Conclusion: The clinical use of PROMs among orthopedic surgeons was negligible, even though an overwhelming majority were interested in using PROMs. The reasons provided included a lack of knowledge on how to use PROMs and the perception that it is too time-consuming to add to regular clinical routine. There should be more efforts towards training surgeons on how to use PROMs, whereas increasing compatibility with existing software tools used by $\mathrm{MOH}$ hospitals may help offset time-related reservations.
\end{abstract}

Keywords: PROM, Total joint arthroplasty, TJA, Patient-reported outcome measures, Use of PROMs, Use by orthopedic surgeons, Saudi Arabia

\section{Background}

As the volume of total joint arthroplasty (TJA) procedures performed in countries across the world continues to increase [1], so has the demand for further evidence of when they are necessary [2]. Patient-reported outcome measures

\footnotetext{
* Correspondence: drfayezalshehri@gmail.com

${ }^{1}$ College of Medicine, Imam Muhammad ibn Saud Islamic University, Riyadh, Kingdom of Saudi Arabia

Full list of author information is available at the end of the article
}

(PROMs) are tools that enable patients to self-report their functional status, pain, and other valuable domains related to their quality of life [3]. With the possibility to be used in both pre- and postoperative settings, PROMs can assist in determining patient satisfaction after TJA by documenting the changes in score and serve as an indicator of the surgical intervention's efficacy [4].

While PROMs are not without their challenges, they remain the best objective tool available for measuring

C C The Author(s). 2020 Open Access This article is licensed under a Creative Commons Attribution 4.0 International License, which permits use, sharing, adaptation, distribution and reproduction in any medium or format, as long as you give appropriate credit to the original author(s) and the source, provide a link to the Creative Commons licence, and indicate if changes were made. The images or other third party material in this article are included in the article's Creative Commons licence, unless indicated otherwise in a credit line to the material. If material is not included in the article's Creative Commons licence and your intended use is not permitted by statutory regulation or exceeds the permitted use, you will need to obtain permission directly from the copyright holder. To view a copy of this licence, visit http://creativecommons.org/licenses/by/4.0/. The Creative Commons Public Domain Dedication waiver (http://creativecommons.org/publicdomain/zero/1.0/) applies to the data made available in this article, unless otherwise stated in a credit line to the data. 
patient centered outcomes according to the International Society of Arthroplasty Registries and various clinicians $[5,6]$. Some of these challenges include choosing the right PROMs that fit the patient population, lack of standardization, and their readability [7, 8].

Still, PROMs continue to empower patients by giving them the ability to become more involved than ever when it comes to their health, by directly contributing to medical and surgical assessments [9].

There is substantial literature surrounding PROM use with regard to evaluating the outcomes in arthroplasty [10-13], but few studies are available regarding its use by orthopedic surgeons for clinical purposes and the barriers they face. Approximately $16 \%$ of surgeons of various specialties in the Middle East currently use PROMs [14], whereas as little as $5.9 \%$ of orthopedic and neurosurgeons routinely use PROMs in the Middle East [15].

In both studies, the Middle East had the lowest percentage of surgeons who use PROMs, with North America and Europe being the highest. Both studies had surgeons citing the lack of time and structural constraints in their institutions as the biggest barriers against using PROMs. The contrast between the similarity in reported barriers and the variation in PROM use across different regions demonstrates that while surgeons ultimately face similar obstacles, the root cause may vary. This creates a need to specifically examine each country separately in order to discern the unique causes that lead to the previously reported barriers. This is especially necessary in regions with variable levels of healthcare such as the Middle East [16].

There are no studies regarding PROM use by orthopedic surgeons in Saudi Arabia. The aim of this study is to identify the prevalence of PROM use by orthopedic surgeons in Saudi Arabia, the reasons behind the use or lack thereof, and the barriers they may face.

\section{Methods \\ Design}

Using a cross-sectional research design with a convenience sampling technique, this study examined the use of patient-reported outcome measures (PROMs) by orthopedic surgeons with regard to its implementation into regular clinical activity and/or using PROMs for research purposes, in addition to barriers they may face, as well as their perceptions regarding PROMs.

A quantitative research approach was conducted using a self-administered survey that is available in both soft and hard copy formats via Google Forms. A prevalidated questionnaire was adapted from a previous study [14]. After obtaining permission to use the questionnaire, it was slightly modified for more applicability, by removing a question regarding mandatory use of PROMs since no such regulations exist by the Ministry of Health $(\mathrm{MOH})$, and a question on whether PROMs are substitute measurements of clinical outcomes. No pilot study was conducted after the removal of these two questions.

\section{Study questionnaire}

The survey included thirty-two items, beginning with a cover letter that provided the details on the objectives of the study, assurances regarding the confidentiality, and anonymity of the collected data. Informed consent was required and collected before moving on to the survey. Participants then proceeded to questions of the first section starting with socio-demographic information, as well as asking orthopedic surgeons on their familiarity with existing universal PROMs and specific PROMs for trauma and orthopedic patients. The last part of the first section asked whether surgeons use PROMs or not, the frequency of the use, and the purposes behind the use (whether it is for clinical activity or research purposes). Branching logic was used to move respondents to section 2-A (surgeons who used PROMs in clinical routine) and section 2-B (surgeons who did not use PROMs in clinical routine) based on their answers in the first section. Both sections contained statements of agreement on reasons for their use of PROMs or lack thereof. In addition, information on two further aspects of PROMs was questioned in the third and fourth sections: aspects that are important in order to implement PROMs in daily clinical routine and the reasons why PROMs are not used more often in daily clinical routine. The questionnaire ended with a question that asked whether surgeons would be interested in using PROMs in daily clinical routine if there was a tool that could overcome the barriers they reported.

Data collection took place between 28 May 2019 and 30 November 2019. The distribution of the questionnaire entailed both on-site visitations to orthopedic departments of hospitals, as well as online correspondence through email, WhatsApp, and social media.

\section{Statistical analysis and sample size calculation}

The margin of error at 95\% confidence (expressing the amount of random sampling error) was computed. Percentages for all categorical variables were computed. To examine the associations between two categorical variables, the chi-square test of independence was used to evaluate the association of "gender," "age," "years of clinical experience," and "area of work" with (A) the familiarity with existing universal PROMs, (B) the familiarity with specific PROMs for trauma and orthopedic patients, and $(\mathrm{C})$ the current use of PROMs in clinical work. The significance level was set at $p<0.05$. All statistical analyses were performed using $\mathrm{R} v$ 3.6.2.

The target population of the study was all the orthopedic surgeons who are employed by $\mathrm{MOH}$ hospitals in 
Riyadh and the Eastern Province. The total number of registered orthopedic surgeons who are employed by the $\mathrm{MOH}$ in Riyadh and the Eastern Province was 399 according to the $\mathrm{MOH}$ statistical yearbook during the time of this study. Sample size calculation was performed using Epi-INFO (Benichou, 2014). Based on an expected prevalence of $50 \%$ (expected prevalence for the use of PROMs) and a significance level of 0.05 , we hypothesized that a sample size of 240 is needed to assess the current use of PROMs with an acceptable error of $4 \%$. We recruited 262 orthopedic surgeons in the current analysis which fulfilled the pre-calculated estimate.

\section{Results}

The study sample included 262 orthopedic surgeons (13.7\% females and $86.3 \%$ males). Surgeons aged $<34$, $35-44$, and $45-54$ years old represented $28.66 \%$, 38.9\%, and $20.2 \%$ of the study sample, respectively. Surgeons from Riyadh represented $63.7 \%$ of the study sample. Less than half of the included surgeons were aware of the existing universal PROMs (40.8\%) and slightly more than half (58\%) were familiar with specific PROMs for trauma and orthopedic patients. The majority of the included surgeons did not use PROMs (69.1\%), and some (17.2\%) used it for research purposes. Only 5\% used it regularly in daily clinical work (Table 1).

Univariate analysis showed that age was significantly associated with knowledge regarding universal $(P=$ $0.002)$ and disease -specific $(P=0.031)$ PROMs. The results showed a consistent increase in the knowledge regarding the universal PROMs. For disease-specific PROMs, knowledge was higher in all age groups compared to the $<34$ years age group. Area of work did not show a statistically significant association with knowledge regarding disease specific PROMs $(P=0.054)$. Similarly, years of experience did not show a statistically significant association with knowledge regarding the universal PROMs $(P=0.058)$ (Table 2).

Only 36 surgeons used PROMs in their clinical routine (irregularly or regularly or both in daily clinical work and research). Their most perceived benefits of using PROMs were prioritizing clinical problems (97\% agreed or strongly agreed) and facilitating communication between surgeons and patients (94\% agreed or strongly agreed). The least perceived advantage was identifying patients' preferences ( $72 \%$ agreed or strongly agreed). The percentage of agreement for the remaining five statements ranged from 81 to $89 \%$ (Table 3).

The top two perceived barriers against using PROMs in daily clinical routine were the long time needed to fill out PROMs (48.9\% agreed and $14.1 \%$ strongly agreed) and the significant change needed to implement PROMs (49.6\% agreed and $12.2 \%$ strongly agreed) (Table 4 ).
Table 1 Summary of demographic and working experience of the study sample

\begin{tabular}{ll}
\hline & $\boldsymbol{N}(\%)$ \\
\hline $\begin{array}{l}\text { Gender } \\
\text { Female }\end{array}$ & $36(13.7 \%)$ \\
Male & $226(86.3 \%)$ \\
Age (years) & \\
$<34$ & $75(28.66 \%)$ \\
35 to 44 & $102(38.9 \%)$ \\
45 to 54 & $53(20.2 \%)$ \\
$>55$ & $32(12.21 \%)$ \\
Years of clinical experience (years) & \\
0 to 4 & $44(16.8 \%)$ \\
5 to 9 & $57(21.8 \%)$ \\
10 to 14 & $69(26.3 \%)$ \\
15 to 19 & $40(15.3 \%)$ \\
20 or more & $52(19.8 \%)$ \\
Familiarity with existing universal PROMs & \\
No & $155(59.2 \%)$ \\
Yes & $107(40.8 \%)$ \\
Familiarity with specific PROMs for trauma and orthopedic \\
patients
\end{tabular}

The results showed that $87 \%$ of the included surgeons would be interested in using PROMs if there was a tool that can overcome the barriers to its use (Fig. 1).

\section{Discussion}

PROM use by surgeons has already been documented in several countries and regions [14, 15, 17], yet no such data exists for Saudi Arabia. Understanding the current status of PROMs among orthopedic surgeons in Saudi Arabia, its use or lack thereof, and the underlaying rationale can lay the groundwork for future research. A sample of 262 orthopedic surgeon who work in Saudi Arabia's Ministry of Health (MOH) hospitals in Riyadh and the Eastern Province revealed that familiarity with specific PROMs for trauma and orthopedic is higher (58\%) than familiarity with universal PROMs (40.8\%), yet a majority (86.3\%) did not use PROMs in their clinical routine. 
Table 2 Factors associated with familiarity and current use of PROMs

\begin{tabular}{|c|c|c|c|c|c|c|c|c|c|}
\hline & Familiarity $\mathrm{v}$ & h universal & ROM & Familiarity & ith specific $P$ & Ms & Current use & & \\
\hline & No & Yes & $P$ & No & Yes & $P$ & No & Yes & $P$ \\
\hline & $N=155$ & $N=107$ & & $N=110$ & $N=152$ & & $N=226$ & $N=36$ & \\
\hline Gender & & & 0.242 & & & 0.386 & & & 0.436 \\
\hline Female & $25(69.4 \%)$ & 11 (30.6\%) & & $18(50.0 \%)$ & 18 (50.0\%) & & 33 (91.7\%) & 3 (8.33\%) & \\
\hline Male & $130(57.5 \%)$ & 96 (42.5\%) & & 92 (40.7\%) & 134 (59.3\%) & & 193 (85.4\%) & 33 (14.6\%) & \\
\hline Age (years) & & & 0.002 & & & 0.031 & & & 0.025 \\
\hline$<34$ & 55 (73.3\%) & 20 (26.7\%) & & 41 (54.7\%) & 34 (45.3\%) & & 70 (93.3\%) & $5(6.67 \%)$ & \\
\hline 35 to 44 & 58 (56.9\%) & 44 (43.1\%) & & 37 (36.3\%) & 65 (63.7\%) & & 90 (88.2\%) & $12(11.8 \%)$ & \\
\hline 45 to 54 & 31 (58.5\%) & 22 (41.5\%) & & $23(43.4 \%)$ & 30 (56.6\%) & & 42 (79.2\%) & 11 (20.8\%) & \\
\hline$>55$ & 11 (34.4\%) & $21(65.6 \%)$ & & 9 (28.1\%) & 23 (71.9\%) & & $24(75.0 \%)$ & 8 (25.0\%) & \\
\hline Clinical experience (years) & & & 0.058 & & & 0.162 & & & 0.137 \\
\hline 0 to 4 & $31(70.5 \%)$ & $13(29.5 \%)$ & & $26(59.1 \%)$ & $18(40.9 \%)$ & & 39 (88.6\%) & $5(11.4 \%)$ & \\
\hline 5 to 9 & $39(68.4 \%)$ & $18(31.6 \%)$ & & $23(40.4 \%)$ & $34(59.6 \%)$ & & $52(91.2 \%)$ & $5(8.77 \%)$ & \\
\hline 10 to 14 & $34(49.3 \%)$ & 35 (50.7\%) & & 27 (39.1\%) & $42(60.9 \%)$ & & 62 (89.9\%) & $7(10.1 \%)$ & \\
\hline 15 to 19 & $25(62.5 \%)$ & 15 (37.5\%) & & $15(37.5 \%)$ & $25(62.5 \%)$ & & $30(75.0 \%)$ & $10(25.0 \%)$ & \\
\hline 20 or more & $26(50.0 \%)$ & $26(50.0 \%)$ & & $19(36.5 \%)$ & $33(63.5 \%)$ & & $43(82.7 \%)$ & $9(17.3 \%)$ & \\
\hline Area of work & & & 0.656 & & & 0.054 & & & 1.000 \\
\hline Eastern Province & $54(56.8 \%)$ & $41(43.2 \%)$ & & $32(33.7 \%)$ & $63(66.3 \%)$ & & $82(86.3 \%)$ & $13(13.7 \%)$ & \\
\hline Riyadh & $101(60.5 \%)$ & $66(39.5 \%)$ & & $78(46.7 \%)$ & 89 (53.3\%) & & $144(86.2 \%)$ & $23(13.8 \%)$ & \\
\hline
\end{tabular}

Statistical analysis was performed using the chi-square test of independence

Current use was defined as using PROMs infrequently/regularly/in clinical routine and research

Our study showed that orthopedic surgeons in the Eastern Province had a higher familiarity with both universal (43.2\%) and disease-specific (66.3\%) PROMs compared to Riyadh's orthopedic surgeons. Despite this gap in familiarity, it appears that there was no difference in the current use of PROMs between the two work areas. This implies that there are more obstacles in the way of clinically implementing PROMs than mere knowledge and awareness. Our data analysis showed that the two main reasons for not using PROMs by orthopedic surgeons in this study were that PROM implementation needs significant changes to the structure of the clinical routine of healthcare providers and in turn leads to further costs $(61.8 \%)$, and that there is no time space for regular implementation (63\%).

Whereas orthopedic surgeons who collected PROMs from their patients were found to have similar motives, such as prioritizing clinical problems (97\%) and facilitating communication between surgeons and patients (94\%). This high level of agreeability suggests that once a successful implementation of PROMs has taken place, the focal point of treatment and care further shifts towards the patient, rather than the disease.

Age was associated with both knowledge and use of PROMs $(p<0.05)$, demonstrating that older orthopedic surgeons are more receptive towards PROMs. This is in

Table 3 Detailed reasons for orthopedic surgeons who collect PROMs in clinical routine

\begin{tabular}{|c|c|c|c|c|c|}
\hline & SD & D & $\mathbf{N}$ & A & SA \\
\hline PROMs can help to prioritize clinical problems. & $0(0 \%)$ & $0(0 \%)$ & $1(2.78 \%)$ & $24(66.7 \%)$ & $11(30.6 \%)$ \\
\hline PROMs can help to facilitate communication between the doctor and the patient. & $0(0 \%)$ & $1(2.78 \%)$ & $1(2.78 \%)$ & $21(58.3 \%)$ & $13(36.1 \%)$ \\
\hline PROMs can screen for potential patient problems. & $0(0 \%)$ & $0(0 \%)$ & $4(11.1 \%)$ & $20(55.6 \%)$ & $12(33.3 \%)$ \\
\hline PROMs can identify a patient's preferences. & $0(0 \%)$ & $0(0 \%)$ & $10(27.8 \%)$ & $17(47.2 \%)$ & $9(25.0 \%)$ \\
\hline PROMs monitor changes/responses to treatment. & $0(0 \%)$ & $2(5.56 \%)$ & $5(13.9 \%)$ & $18(50.0 \%)$ & $11(30.6 \%)$ \\
\hline $\begin{array}{l}\text { PROMs monitor the general healthcare status of my patients and their healthcare } \\
\text { status changes. }\end{array}$ & $0(0 \%)$ & $1(2.78 \%)$ & $5(13.9 \%)$ & $22(61.1 \%)$ & $8(22.2 \%)$ \\
\hline PROMs help to monitor the quality of healthcare provision. & $0(0 \%)$ & $1(2.78 \%)$ & $4(11.1 \%)$ & $21(58.3 \%)$ & $10(27.8 \%)$ \\
\hline PROMs are useful for national/international comparison and benchmarking. & $0(0 \%)$ & $2(5.56 \%)$ & $3(8.33 \%)$ & $21(58.3 \%)$ & $10(27.8 \%)$ \\
\hline
\end{tabular}


Table 4 Perceived barriers for not using PROMs in daily clinical routine

\begin{tabular}{|c|c|c|c|c|c|}
\hline & SD & D & $\mathrm{N}$ & A & SA \\
\hline Data from PROMs are subjective; they cannot adequately reflect an individual's situation. & $10(3.82 \%)$ & $71(27.1 \%)$ & $88(33.6 \%)$ & $74(28.2 \%)$ & $19(7.25 \%$ \\
\hline $\begin{array}{l}\text { Orthopedic surgeons lack the necessary skills to interpret and use the information given } \\
\text { by these instruments. }\end{array}$ & $18(6.87 \%)$ & $73(27.9 \%)$ & $69(26.3 \%)$ & $86(32.8 \%)$ & 16 \\
\hline To fill out PROMs is time-consuming and burdensome for the patients. & $3(1.15 \%)$ & $31(11.8 \%)$ & $63(24.0 \%)$ & $128(48.9 \%)$ & $37(14.1$ \\
\hline $\begin{array}{l}\text { plementing PROMs would require significant } c \\
\text { nical routine of healthcare providers as well as }\end{array}$ & $2(0.76 \%)$ & $41(15.6 \%)$ & $57(21.8 \%)$ & $130(49.6 \%)$ & $32(12.2 \%$ \\
\hline
\end{tabular}

$S D$ strongly disagree, $D$ disagree, $N$ neutral, $A$ agree, $S A$ strongly agree

contrast to a previous study by the AO Foundation that found no significant influence between the level of clinical experience and the use of PROMs, which further corroborate their speculation regarding collection of PROMs by less experienced clinicians on behalf of more senior ones in order to explain such a finding. Additionally, while PROM use by surgeons was found to be generally low in other countries, Saudi Arabian orthopedic surgeons are comparatively lower [14].

Surgical specialization may factor in both familiarity and use, especially in fields with well-established PROMs. Zwiers et al. (2018) reported that 188 feet and ankle surgeons were familiar with 20 different PROMs, and $72 \%$ of the respondents used PROMs, with $39 \%$ of them using it in regular clinical routine [17]. In contrast, Joeris et al. (2018) found that craniomaxillofacial surgeons had both low familiarity (31.7\%) and use (15.4\%), which was attributable to the lack of well-established PROMs for their patients [14]. In our study, Saudi orthopedic surgeons did not subscribe to this wellknown link in the literature. While there are well- established PROMs for joint function and pain such as the Oxford Knee Score [18] and the Oxford Hip Score [19], orthopedic surgeons in Saudi Arabia remain relatively less familiar with these disease-specific PROMs (58\%) with little use in clinical work (13.74\%). This may imply that training programs, seminars, courses, and other forms of continuing medical education related to orthopedics in Saudi Arabia have not yet discussed PROMs sufficiently or at length. Interestingly, geographical regions have also been shown to affect familiarity and use, especially in countries that have started a PROM collection program, such as the Patient-Reported Outcomes Measurement Information System (PROMIS) program in the United States of America (USA) [20], and the national PROM program in the United Kingdom (UK) [21]. This may be a more likely explanation for the relatively poor rates of Saudi orthopedic surgeons' familiarity and use of PROMs in comparison with their counterparts in North American and European countries since Saudi Arabia has yet to start a similar collection program.

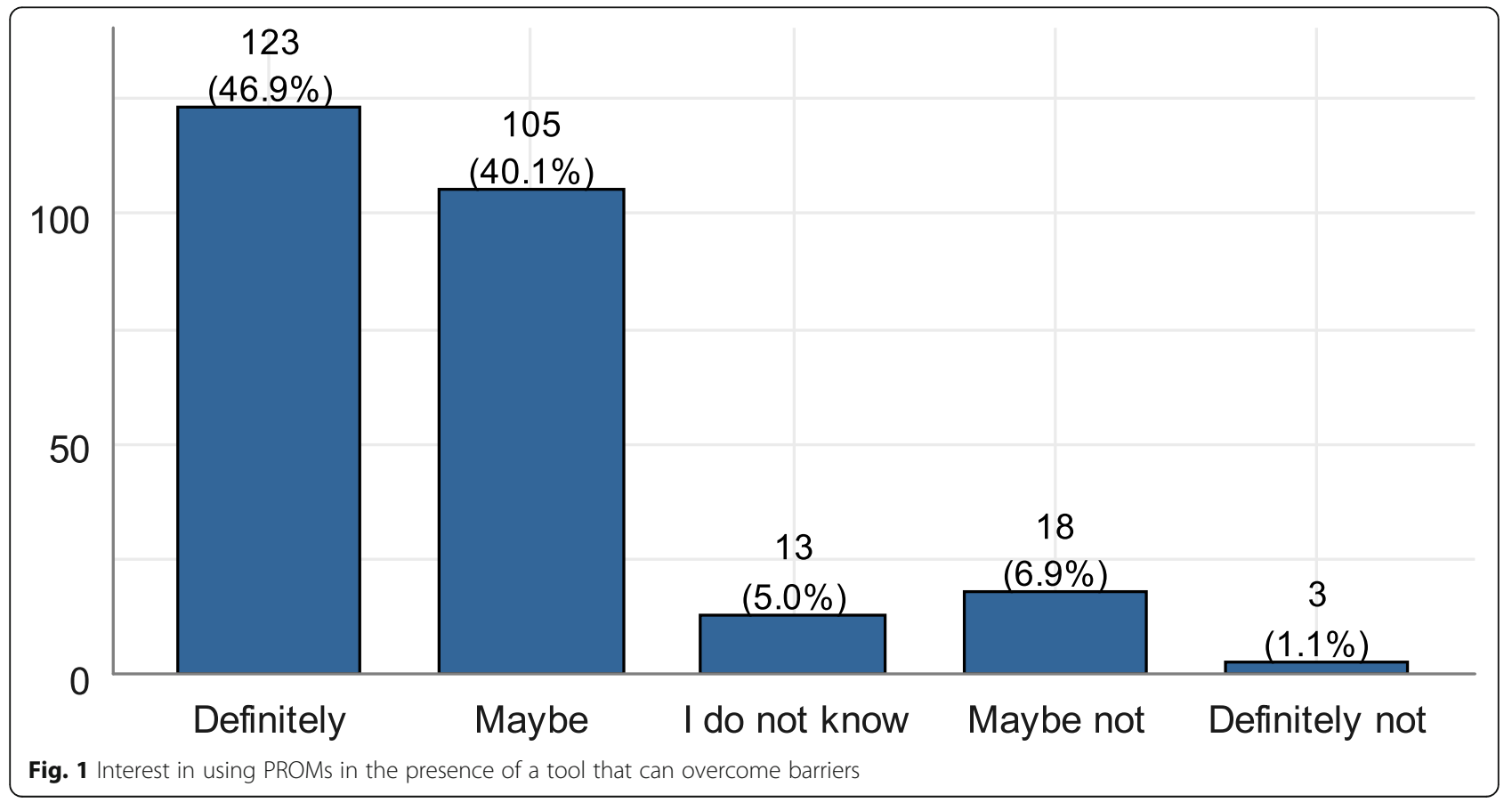


One of the main limitations this study faces is the inability to cover $\mathrm{MOH}$ hospitals in other regions as well as private hospitals. While there is a notable effort to grant further regional autonomy on the directorate level, $\mathrm{MOH}$ hospitals remain largely uniform in policies and protocol [22]. Compounding the aforementioned with the fact that Riyadh and the Eastern Province are two of the largest regions in Saudi Arabia, it should be safe to assume that variation among other regions should not be statistically significant. In contrast, private hospitals are wholly independent, and there might be incentive to use PROMs due to contractual agreements with health insurance companies, as is the case in other countries [23].

Another limitation is the removal of two items in the branching logic part of the adapted questionnaire without revalidating the survey to ensure cultural compatibility, such as an item regarding the existence of regulations mandating PROM use in the surgeon's hospital. The original survey's target population was surgeons from multiple specialties such as spine, trauma, craniomaxillofacial, and orthopedics from countries all over the world. While the international nature of the original study gave little reason to revalidate the survey for local Saudi orthopedic surgeons, it is possible that future studies with a more culturally mindful design may yield new findings.

Further research in other regions to validate assumptions revealed by this study is needed, as well as examining in further detail the specific structure of clinical routine in $\mathrm{MOH}$ hospitals, which many orthopedic surgeons cited as requiring significant change for a successful implementation of PROMs.

\section{Conclusion}

Our survey reveals that regular use of PROMs among orthopedic surgeons was exceptionally low, even though the majority were interested in using them. The main reasons included the lack of knowledge, the belief that collecting PROMs is too time-consuming, and that it requires a significant as well as costly overhaul to the structure of their clinical activity. One way to overcome these obstacles in $\mathrm{MOH}$ hospitals is to implement an integrated computer-based collection system and to further highlight the clinical importance of such tools and how to use them.

\section{Abbreviations}

PROMs: Patient-reported outcome measures; TJA: Total joint arthroplasty; $\mathrm{MOH}$ : Ministry of Health

\section{Acknowledgements}

Not applicable

\section{Authors' contributions}

All authors designed the study and collected and analyzed the data. FA wrote the manuscript. MA supervised the study. All authors read and approved the final manuscript.

\section{Funding}

This research did not receive any specific grant from funding agencies in the public, commercial, or not-for-profit sectors.

\section{Availability of data and materials \\ The datasets used during the current study are available from the corresponding author on reasonable request.}

Ethics approval and consent to participate

The study protocol was approved by the institutional review board at King Fahad Hospital, Al-Hofuf, Saudi Arabia (No. 15/A-19-2019).

\section{Consent for publication}

All authors provide consent for publication.

\section{Competing interests}

The authors declare that they have no competing interests

\section{Author details}

'College of Medicine, Imam Muhammad ibn Saud Islamic University, Riyadh, Kingdom of Saudi Arabia. ${ }^{2}$ Department of Orthopedic Surgery, King Fahad Hospital, Hofuf, Kingdom of Saudi Arabia.

Received: 30 September 2020 Accepted: 30 November 2020

Published online: 10 December 2020

\section{References}

1. Inacio MCS, Graves SE, Pratt NL, Roughead EE, Nemes S. Increase in total joint arthroplasty projected from 2014 to 2046 in Australia: a conservative local model with international implications. Clin Orthop Relat Res. 2017; 475(8):2130-7. https://doi.org/10.1007/s11999-017-5377-7.

2. Ghomrawi HMK, Mushlin Al, Kang R, et al. Examining timeliness of total knee replacement among patients with knee osteoarthritis in the U.S. results from the OAI and MOST longitudinal cohorts. J Bone Joint Surg Am. 2020;102(6):468-76. https://doi.org/10.2106/JBJS.19.00432.

3. Lyman S, Hidaka C. Patient-reported outcome measures-what data do we really need? J Arthroplasty. 2016;31(6):1144-7. https://doi.org/10.1016/j.arth. 2016.01.073.

4. Davis EP, Freedhand AM, Rodriguez-Quintana D, Noble PC. Achieving satisfaction with patient-reported outcomes: PROMS. In: Scuderi G, Tria A, Cushner F, editors. Rapid Recovery in Total Joint Arthroplasty. Cham: Springer; 2020. https://doi.org/10.1007/978-3-030-41223-4_20.

5. Rolfson O, Eresian Chenok K, Bohm E, Lübbeke A, Denissen G, Dunn J, et al. Patient-reported outcome measures in arthroplasty registries. Acta Orthop. 2016;87:3e8. https://doi.org/10.1080/17453674.2016.1181815.

6. Hamilton DF, Giesinger JM, Giesinger K. It is merely subjective opinion that patient-reported outcome measures are not objective tools. Bone Joint Res. 2017;6(12):665-6. https://doi.org/10.1302/2046-3758.612.BJR-2017-0347 PMID: 29212762; PMCID: PMC5935812.

7. Siljander MP, McQuivey KS, Fahs AM, Galasso LA, Serdahely KJ, Karadsheh MS. Current trends in patient-reported outcome measures in total joint arthroplasty: a study of 4 major orthopaedic journals. J Arthroplasty. 2018; 33(11):3416-21. https://doi.org/10.1016/j.arth.2018.06.034.

8. Perez JL, Mosher ZA, Watson SL, et al. Readability of orthopaedic patientreported outcome measures: is there a fundamental failure to communicate? Clin Orthop Relat Res. 2017;475(8):1936-47. https://doi.org/ 10.1007/s11999-017-5339-0.

9. Wilson I, Bohm E, Lübbeke A, et al. Orthopaedic registries with patientreported outcome measures. EFORT Open Rev. 2019;4(6):357-67. Published 2019 Jun 3 10.1302/2058-5241.4.180080.

10. Eskelinen A. Pearls: How to make the most of PROMs in everyday clinical practice. Clin Orthop Relat Res. 2019;477(7):1563-5. https://doi.org/10.1097/ CORR.0000000000000847.

11. - Hamilton DF, Lane JV, Gaston P, et al. What determines patient satisfaction with surgery? A prospective cohort study of 4709 patients following total joint replacement. BMJ Open. 2013;3(4):e002525. Published 2013 Apr 9. doi: https://doi.org/10.1136/bmjopen-2012-002525.

12. Galea VP, Rojanasopondist $\mathrm{P}$, Connelly JW, et al. Changes in patient satisfaction following total joint arthroplasty. J Arthroplasty. 2020;35(1):32-8. https://doi.org/10.1016/j.arth.2019.08.018. 
13. Lyman S, Yin KL. Patient-reported outcome measurement for patients with total knee arthroplasty. J Am Acad Orthop Surg. 2017;25(Suppl 1):S44-7. https://doi.org/10.5435/JAAOS-D-16-00637.

14. Joeris A, Knoll C, Kalampoki V, et al. Patient-reported outcome measurements in clinical routine of trauma, spine and craniomaxillofacial surgeons: between expectations and reality: a survey among 1212 surgeons. BMJ Open. 2018;8:e020629. https://doi.org/10.1136/bmjopen-2017-020629.

15. Falavigna A, Dozza DC, Teles AR, et al. Current status of worldwide use of patient-reported outcome measures (PROMs) in spine care. World Neurosurg. 2017;108:328-35. https://doi.org/10.1016/j.wneu.2017.09.002.

16. Kronfol NM. Access and barriers to health care delivery in Arab countries: a review. East Mediterr Health J. 2012;18(12):1239-46. https://doi.org/10. 26719/2012.18.12.1239 PMID: 23301399

17. Zwiers R, Weel H, Mallee WH, Kerkhoffs GMMJ, van Dijk CN. Ankle platform Study Collaborative - Science of Variation Group. Large variation in use of patient-reported outcome measures: a survey of 188 foot and ankle surgeons. Foot Ankle Surg. 2018;24(3):246-51. https://doi.org/10.1016/j.fas. 2017.02.013.

18. Harris KK, Dawson J, Jones LD, et al. Extending the use of PROMs in the NHS - using the Oxford Knee Score in patients undergoing non-operative management for knee osteoarthritis: a validation study. BMJ Open. 2013;3: e003365. https://doi.org/10.1136/bmjopen-2013-003365.

19. Murray DW, Fitzpatrick R, Rogers $K$, et al. The use of the Oxford hip and knee scores. J Bone Joint Surg Br. 2007;89(8):1010-4. https://doi.org/10.1302 0301-620X.89B8.19424.

20. Alonso J, Bartlett SJ, Rose M, et al. The case for an international PatientReported Outcomes Measurement Information System (PROMIS ${ }^{\bullet}$ ) initiative. Health Qual Life Outcomes. 2013;11:210. Published 2013 Dec 20. https://doi. org/10.1186/1477-7525-11-210

21. Kyte $D$, Cockwell $P$, Lencioni $M$, et al. Reflections on the national patientreported outcome measures (PROMs) programme: where do we go from here? Journal of the Royal Society of Medicine. 2016;109(12):441-5. https:/ doi.org/10.1177/0141076816677856.

22. Almalki M, Fitzgerald G, Clark M. Health care system in Saudi Arabia: an overview. East Mediterr Health J. 2011;17(10):784-93 10.26719/2011.17.10. 784

23. Smith JT, Abdurrob A. Correlation of health insurance provider to orthopedic patient reported outcome measures. Foot \& Ankle Orthopaedics. October 2019. https://doi.org/10.1177/2473011419S00069.

\section{Publisher's Note}

Springer Nature remains neutral with regard to jurisdictional claims in published maps and institutional affiliations.

Ready to submit your research? Choose BMC and benefit from:

- fast, convenient online submission

- thorough peer review by experienced researchers in your field

- rapid publication on acceptance

- support for research data, including large and complex data types

- gold Open Access which fosters wider collaboration and increased citations

- maximum visibility for your research: over $100 \mathrm{M}$ website views per year

At BMC, research is always in progress.

Learn more biomedcentral.com/submissions 